\title{
THE EFFECT OF GLYCOLIC ACID AND VITAMIN C TOPICAL IN FRECKLES EFFICACY
}

\author{
Tiffani Sandradewi Wignjosoesastro ${ }^{1 *}$, Widyawati ${ }^{2}$, Rahmat Sugianto $^{2}$ \\ ${ }^{1}$ Undergraduate Program, Faculty of Medicine, Diponegoro University, Semarang, Indonesia \\ ${ }^{2}$ Department of Dermatology and Venereology, Faculty of Medicine, Diponegoro University, Semarang, Indonesia \\ *Corresponding author, E-mail: $\underline{\text { sandradewiwignjo@students.undip.ac.id }}$
}

\begin{abstract}
Background: Freckles are small dark-spot hyperpigmentation on the face, upper body, and back of the hands. This hyperpigmentation develops as a result of melanocyte activity by the combination of genetic predisposition located on the basal layer and sun exposure. Glycolic acid and vitamin $\mathrm{C}$ are widely used as a depigmentation agent. The component of vitamin $\mathrm{C}$ is unstable, hence, it is often used more effective when it binds to other depigmentation agents, such as glycolic acid to develop better depigmentation Objective: The aim of this study was to prove the efficacy of combination of glycolic acid and vitamin C in freckles. Methods: True experimental study with one group pre and posttest group design. Fifteen freckles patients with inclusion and exclusion criteria received combination therapy of glycolic acid and vitamin $\mathrm{C}$ topical for 30 days. Clinical evaluation using Freckles Refinement Score and photography was recorded before and after therapy. The statistical analyses used was Wilcoxon test. Results: There was a significant value $(p=0.000)$ for improvement of the Freckles Refinement Score after received the combination of glycolic acid and vitamin $\mathrm{C}$ topical. Conclusion: The combination of glycolic acid and vitamin $\mathrm{C}$ was effective for Freckles.
\end{abstract}

Keywords : Freckles, Glycolic Acid, Vitamin C, Treatment.

\section{INTRODUCTION}

Freckles or ephelides are pigmented spot in the basal layer of the skin, that common in type 1 and 2 of Fitzpatrick skin types. Overproduce melanin without the increased number of melanocytes, changing the color of the outer skin cells formed freckles. Generally found in children before puberty. The formation of freckles is caused by exposure to sunlight.[1] Freckles are predominantly found on any skin exposed to the sun, such as the face, shoulders, and arms. The one who has never developed freckles may develop them suddenly following extended exposure to sunlight.[2]

Freckles treatment is challenging, depigmentation agents inhibit the tyrosine enzyme, such as hydroquinone. The side effects of hydroquinone are skin irritations, rebound phenomenon, and ochronosis.[3] Kojic acid can cause contact dermatitis and have the mutagen complexion.[4] The use of chemical peeling will cause temporary skin problems. [5] Until now, any satisfactory therapy has not been found, it is necessary to look for other depigmentation agents with high effectiveness and fewer side effects. In this brief report, we present the combination of glycolic acid and vitamin $\mathrm{C}$ as a freckles treatment.

Vitamin $\mathrm{C}$ is widely used as a depigmentation agent because of its interaction with $\mathrm{Cu}$ ion at the site of tyrosinase, thereby reducing melanin formation. However, the vitamin $\mathrm{C}$ components are unstable. Therefore, it is often combined with other

depigmentation agents to produce a better depigmentation effect, such as glycolic acid. Glycolic acid has keratolytic abilities that naturally induce epidermolysis, damage melanin in the basal layer, and increase collagen synthesis. The aim of this study to establish the efficacy of glycolic acid combined with vitamin $\mathrm{C}$ topical in freckles treatment.

\section{METHODS AND MATERIALS}

This study is a true experimental with one group pre and post-test group design. The amount of the patients are calculated with a single sample formula. Fourteen patients with freckles in Diponegoro National Hospital were recruited over the course. Drop out is anticipated with the enhancement of one patient, so the total is fifteen patients. These patients were otherwise in good health and willing to receive treatment. Patients who used any topical bleaching creams or freckles treatment within the past two weeks, have an allergy towards the topical agent and currently do not suffer from other skin problems, such as contact dermatitis allergy, atopic dermatitis, psoriasis, and iktoris vulgaris were all-excluded. 
Volume 10, Number 1, January 2021

The materials used in this research were $8 \%$ glycolic acid and $10 \%$ vitamin $\mathrm{C}$. The observation tools used were an informed consent sheet, Freckles Refinement Score sheet based on Freckles Severity Index, and a camera for the observation.

Photographs were taken pre-treatment and one month after $8 \%$ glycolic acid cream and $10 \%$ vitamin $\mathrm{C}$ serum topical treatment. Glycolic acid applied to the area of the freckles lesion for about 5 to 10 minutes, continued with 3 to 4 drops of the vitamin $\mathrm{C}$ serum to all surfaces of the face. Performed in the morning and night, patients were followed clinically for a total of 30 days. Sunblock SPF 30 was applied in the morning and reapplied during the afternoon. Treatment efficacy and patient satisfaction were evaluated using photographs and Freckles Refinement Score questionnaires. The primary data will be evaluated using SPSS 26.0 program.

\section{RESULTS}

During the procedure, fifteen patients noted with combination of glycolic acid and vitamin $\mathrm{C}$ topical treatment based on inclusion and exclusion criteria. Included the application of Sunblock SPF 30. At thirty days post-treatment, all the patients were evaluated.

Table 1. Freckles Severity Scale Before and After Treatment

\begin{tabular}{cccc}
\hline Variable & \multicolumn{2}{c}{$\begin{array}{c}\text { Median of Freckles } \\
\text { Refinement Score }\end{array}$} & \multirow{P}{*}{} \\
\cline { 2 - 3 } & Pre-test & Post-test & \\
\hline Subject & $.0000(1.00-$ & $1.8667(1.00$ & $.000^{*}$ \\
& $2.00)$ & $-2.00)$ & \\
\hline Explanation : *significant $(p, 0,05) ;$ Wilcoxon test
\end{tabular}

Table 1. Shows the median of the pre-test and post-test Freckles Refinement Score. The score indicates a significant improvement in the freckles severity scale. Wilcoxon test refers to the significant difference in freckles patient $(p=0,000)$.

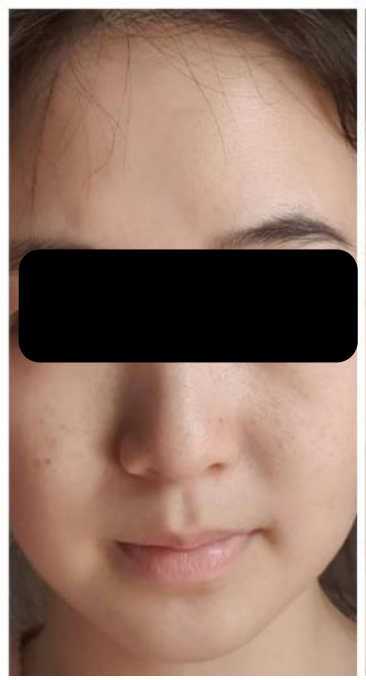

(a)

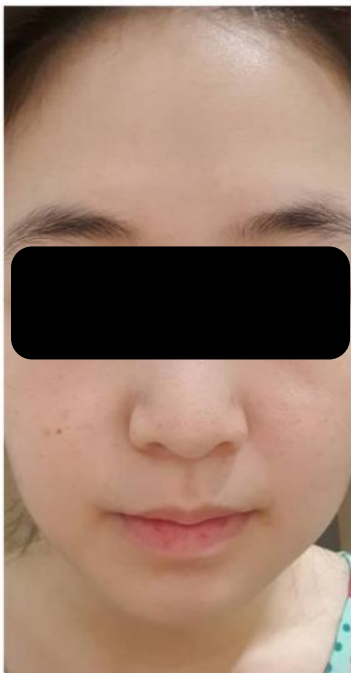

(b)
Figure 1. The appearance of freckles before (a) and after glycolic acid and vitamin $\mathrm{C}$ treatment (b).

Figure 1 shows a representation at before and after application of glycolic acid and vitamin $\mathrm{C}$ to the freckles lesion for 30 days. The overall treatment improvement of the combination of glycolic acid and vitamin $\mathrm{C}$ statically significant. No patient was found to have any evidence of inflammation. No post-inflammatory hyper and hypopigmentation, or recurrence was observed.

\section{DISCUSSION}

There was a statistically Refinement Score improvement after the treatment. The same result with the previous research shows significant enhancement in of hyperpigmentation improvement by a combination instrument of glycolic acid and vitamin C.[6]

The result of this research is corresponding with the theoretical basis that topical glycolic acid and vitamin $\mathrm{C}$ are depigmentation agents that can be used as freckles therapy. The combination of glycolic acid and vitamin $\mathrm{C}$ in freckles therapy works synergically. [7,8] Each agent has its own charge and system as a depigmentation agent. Glycolic acid has a keratolytic effect, naturally induces epidermolysis, destroys basal layer melanin, and increases dermal collagen synthesis. On the other hand, vitamin $\mathrm{C}$, the most plentiful antioxidant prevents the formation of melanin.[9] Vitamin $\mathrm{C}$ is essentially safe and effective to prevent pigment formation due to sunlight. Clinical studies have also shown that vitamin $\mathrm{C}$ has a brightening effect on the skin and effective to inhibit the melanogenesis 
mechanism, being an inhibitor of tyrosinase, thereby decreasing the melanin formation and the intermediation of melanin such as dopaquinone.[10] The component of vitamin $\mathrm{C}$ is unstable, hence, it is often used more effective when it binds to other depigmentation agents, such as glycolic acid to develop better depigmentation.[11]

However, the clinical experience of Glycolic Acid and Vitamin C combination on freckles is very limited. Regardless, the use of sunblock SPF 30 is very substantial in this research. Sunblock is very effective to prevent the exposure of direct sunlight because it contains a physical barrier and it is good for daily use. [12]

The limitation of the research was monitored through photos so that it could not be observed directly. All of the activities of these research subjects, such as sun exposure and the drug applications could be diverse and it was not controlled. Besides, the measurement of the severity of freckles was subjectively observed. Consequently, a prospective study is needed to validate the objectivity.

\section{CONCLUSION}

In conclusion, this research proves that there is a significant score increase in Freckles Refinement Score. The combination of $8 \%$ glycolic acid and $10 \%$ vitamin $\mathrm{C}$ results was effective and quick modality for significant improvement of freckles treatment when used topically within 30 days.

\section{Ethical Approval}

This research is ethical approved by the Ethics Committee from the Medical Faculty of Diponegoro University. Research license was given on June 15th, 2020 with number No. 132/EC/KEPK/FKUNDIP/VI/2020.

\section{Conflicts of Interest}

The authors declare no conflict of interest.

\section{Funding}

No specific funding was provided for this article.

\section{Author Contributions}

All authors conceived and designed the study. TS conducted the experiments, analyzed the data and wrote the paper. The authors wish to thank Dr. Julian Dewatiningrum, Department of Obstetrics and Gynaecology for the supervision. The authors also gratefully acknowledge the dedicated efforts of all the volunteers, the investigators and the staff members involved in this study. All authors contributed to manuscript revisions. All authors approved the final version of the manuscript and agree to be held accountable for the content therein.

\section{REFERENCES}

1. Kang S, Amagai M, Bruckner AL, H. Enk A. Fitzpatrick Dermatology 9th Edition. 2019;

2. Ezzedine K, Mauger E, Latreille J, Jdid R, Malvy D, Gruber F, et al. Freckles and solar lentigines have different risk factors in Caucasian women. J Eur Acad Dermatology Venereol. 2013; 27(3):

3. Wardhani PH. Pilihan Terapi Hiperpigmentasi Pascainflamasi pada Kulit Berwarna (Treatment Options for Postinflammatory Hyperpigmentation in Color Skin). Berk Ilmu Kesehat Kulit dan Kelamin. 2016; 28:

4. Lynde CB., J.N. Kraf Md, Lynde, C.W., MD F. Topical Treatment for Melasma and Postinflammatory Hyperpigmentation. Top Treat Melasma Postinflammatory Hyperpigmentation. Skin Therapy Letter. 2006. 11;9

5. Bandem A. Analisis pemilihan terapi kelainan kulit hiperpigmentasi. Medicinus. 2013; 26: 47-52.

6. Sobhi RM, Sobhi AM. A single-blinded comparative study between the use of glycolic acid $70 \%$ peel and the use of topical nanosome vitamin $\mathrm{C}$ iontophoresis in the treatment of melasma. J Cosmetic Dermatology. 2012;11(1): 65-71.

7. Telang PS. Vitamin C in dermatology. Indian Dermatology Journal. 2013; 4(2): 143-7.

8. Sharad J. Glycolic acid peel therapy - A current review. Vol. 6, Clinical, Cosmetic and Investigational Dermatology. Dove Press; 2013. hal. 281-8.

9. Sarkar R, Parmar N V., Kapoor S. Treatment of Postinflammatory Hyperpigmentation With a Combination of Glycolic Acid Peels and a Topical Regimen in Dark-Skinned Patients. Dermatologic Surg= 2017; 43(4): 566-73.

10. Yi N, Chiang Z. Topical Vitamin $\mathrm{C}$ and The Skin: Mechanisms of Action and CLinical Application. J Clin Aesthet Dermatol. 2017; 14(7): $14-17$

11. De Dormael R, Bastien $P$, Sextius $P$, Gueniche A, Ye D, Tran C, et al. Vitamin C prevents ultraviolet-induced pigmentation in healthy volunteers: Bayesian meta-analysis results from 31 randomized controlled versus 
vehicle clinical studies. J Clin Aesthet Dermatol. 2019;12(2): E53-9.

12. Sarkar R, Garg V, Bansal S, Sethi S, Gupta C. Comparative evaluation of efficacy and tolerability of glycolic acid, salicylic Mandelic acid, and Phytic acid combination peels in Melasma. Dermatol Surg. 2016; 42(3): 384-91. 